O eixo e a roda, Belo Horizonte, v. 24, n. 2, p. 15-30, 2015

\title{
Realismos em 1870: em torno de $O$ Gaúcho, de José de Alencar
}

\section{Realisms in 1870: around $\mathrm{O}$ Gaúcho, by José de Alencar}

Marcus Vinicius Soares

Universidade do Estado do Rio de Janeiro (UERJ), Rio de Janeiro, Rio de Janeiro, Brasil. soaresmarcus@hotmail.com

Resumo: O presente artigo consiste na análise do debate literário ocorrido a partir dos anos 70 do século XIX entre a abordagem crítica orientada pelos preceitos do Realismo e do Naturalismo, que começam a transitar no Brasil, e as produções ficcionais que ainda seguiam a diretriz romântica. Para o nosso objetivo, destacaremos a obra do autor que, à época, era o mais significativo representante do romantismo brasileiro, José de Alencar, em especial o modo como a sua obra foi recebida nesse contexto, sobretudo $O$ gaúcho, romance publicado em 1870, cuja repercussão nos possibilita entender a diversidade de ideias sobre literatura que circulavam no período.

Palavras-chave: realismo oitocentista; José de Alencar; crítica literária.

Abstract: The present article deals with the literary debate, from the 1870 s on, between criticism informed by the assumptions of Realism and Naturalism, and fictional works that were still in tune with the principles of Romanticism. We will dwell on the work of the most distinguished romantic novelist in Brazil, José de Alencar. We will primarily stress the reception of his novels, especially of O gaúcho, published in 1870, whose repercussion allows us to understand the diversity of ideas about literature that were current during this historical period.

Keywords: nineteenth-century realism; José de Alencar; literary criticism. 
Recebido em 26 de maio de 2015. Aprovado em 11 de agosto de 2015.

\section{Entre Richardson e Zola}

“A imaginação foi substituída pela observação e a observação é a alavanca mais forte da ciência. A literatura deve pois ser científica, isto é, as letras devem empregar o método das ciências" (LIMA, 1881, p. 1). O trecho citado é de autoria de Alcides Lima e corresponde ao final de artigo publicado na seção folhetim do jornal Província de São Paulo, em 26 de maio de 1881. Trata-se de uma resenha ao romance $O$ mulato, de Aluísio Azevedo, que saiu meses antes na cidade de São Luís, capital do Maranhão. ${ }^{1}$ Advogando em favor das realizações literárias do naturalismo no Brasil, Lima entende que $O$ mulato pode ser considerado uma de suas manifestações, apesar de persistir em sua narrativa traços do romantismo moribundo. Sob esse prisma, segundo o crítico, se, por um lado, Azevedo acerta na simplicidade inicial do enredo e na singeleza de algumas descrições, sobretudo de cenários, por outro, equivoca-se no desenvolvimento da história e na inverossimilhança da construção dos personagens. No primeiro caso, prevalece a excelência do autor em detectar um conflito "natural", uma vez que disseminado na sociedade brasileira; no segundo, prepondera a falta de técnica na medida em que Azevedo perde de vista essa mesma "naturalidade" ao introduzir na narrativa, a partir de determinado momento, inúmeras peripécias, conduzidas pelas ações vigilantes de "entidades sobre-humanas" (LIMA, 1881, p. 1) tipicamente românticas, os tradicionais vilões, encarnados aqui nas figuras do cônego Diogo e do caixeiro Dias. Para o crítico gaúcho, o desvio de rota e a ênfase dada a esses personagens enfraquecem o texto em face da nova concepção do gênero:

O romance não é mais um conto imaginoso, nem uma ficção poética. É a própria ciência sob uma fórmula literária. É o livro da época, um dos monumentos do século. A ficção, pois, será sempre condenável. No Mulato ela é, infelizmente, um elemento preponderante. (LIMA, 1881, p. 1)

\footnotetext{
${ }^{1} \mathrm{O}$ livro foi publicado pela Tipografia do jornal maranhense $O$ País, que pouco depois reproduziria a resenha de Alcides Lima em suas páginas.
} 
Conjugando as duas citações, é plausível aferir que, sendo o romance "a própria ciência sob uma fórmula literária", essa fórmula não seria outra senão a observação aplicada aos procedimentos específicos da elaboração romanesca. Assim, não é apenas o conceito de romance que se altera com o advento do naturalismo, mas o estatuto mesmo de literatura que migra da esfera dos produtos da imaginação para os do entendimento. ${ }^{2}$ Mas em que medida essa alteração corresponderia a uma novidade considerando o desenvolvimento da literatura nos últimos dois séculos?

Como não poderia deixar de ser, Alcides Lima parece seguir bem de perto a cartilha propugnada por Émile Zola - não é à toa que ele abre a resenha felicitando a recente iniciativa da imprensa brasileira de publicar dois romances do autor francês, L'Assomoir e Nana. Entretanto, a fórmula que ele julga orientar a elaboração de romances não se coaduna com as proposições do autor de Thérèse Raquin. Uma breve incursão pelo famoso ensaio "O romance experimental", permite-nos assinalar que, embora considere a importância da observação no método naturalista de escrita romanesca, Zola entende que ela é o estágio anterior com base no qual a experiência deve ser desenvolvida pelo escritor. Quer dizer, uma vez observado um fenômeno qualquer, o romancista deve intervir com o intuito de estabelecer as leis que o determinam, instituindo assim os enlaces possíveis no decorrer da trama. Como sentencia Zola, "o romancista sai em busca de uma verdade" (ZOLA, 1982, p. 31) e afirmá-la é consequência do procedimento experimental da ciência aplicado ao romance. Ora, se a observação pura e simples não seria suficiente para conceder status naturalista a um romance, de onde vem tal atribuição utilizada, mesmo que parcialmente, por Alcides Lima para qualificar $O$ mulato ${ }^{3}$

$\mathrm{Na}$ verdade, o estatuto da observação em literatura, especialmente no romance, vem de longe e não seria nenhuma surpresa encontrá-lo como elemento de reflexão, por exemplo, em Denis Diderot. Em ensaio de 1762, intitulado "Elogio a Richardson", as ponderações apresentadas

\footnotetext{
${ }^{2}$ Para que não se pense que a migração diz respeito apenas ao romance, o livro de Izidoro Martins Junior, A poesia científica, cuja primeira edição é de 1883, sustenta a mesma concepção, uma vez que entende que a poesia de sua época corresponde "ao período da ciência ou ao estado positivo a que chegaram hoje os povos do Ocidente." (MARTINS JUNIOR, 1914, p. 23).

${ }^{3}$ Nunca é demais recordar que $O$ mulato consta em quase todos manuais de historiografia literária como sendo o primeiro romance naturalista brasileiro.
} 
pelo filósofo iluminista sobre a obra do romancista inglês podem ser tomadas como substrato do que vai nortear a trajetória do romance na segunda metade do século XVIII e no decorrer do XIX. Considerando o caráter quimérico e frívolo do que vinha sendo chamado de romance até então e a pergunta sobre se a mesma rubrica ainda seria válida para as realizações de Richardson, Diderot destaca o que as diferencia: ao invés do distanciamento imaginoso das antigas narrativas romanescas, o que se mostra no autor de Pamela é a proximidade do "mundo em que nós vivemos", da verdade do drama, da "realidade possível" das personagens e das "figuras tomadas do âmbito da sociedade" (DIDEROT, 2000, p. 17). Da perspectiva de Alcides Lima, não seriam características válidas como elogio à "naturalidade" de $O$ mulato em 1881 ? E por que elas seriam ainda úteis como padrão crítico ao romance de Azevedo quando, supostamente, elas já deveriam ter sido superadas pelo naturalismo vigente, no qual a ciência experimental seria o modelo privilegiado? ${ }^{4}$

$\mathrm{Na}$ tentativa de compreender o pensamento literário de Zola, é possível que o dado experimental tenha passado despercebido ao resenhista gaúcho. Contudo, é possível também que o problema não seja apenas de boa ou má interpretação da obra do escritor francês. Isso porque no artigo de Alcides Lima dois conceitos são empregados como contraponto aos que são valorizados como definição do romance contemporâneo e que acabam sobressaindo em seu texto como se, para o crítico, negá-los fosse mais importante do que afirmar o ideal naturalista: trata-se dos conceitos de romantismo e imaginação. Empregados como sinônimos por Lima, entende-se por que o critério observacional é encarado por ele como novidade no início da década de 1880 e não como retomada do pressuposto realista com base no qual Diderot assinalaria no século anterior o ineditismo dos romances de Richardson em direta oposição à desbragada imaginação com que os exemplares do gênero vinham sendo produzidos. E, embora a nomenclatura não sofra alteração como queria o iluminista francês, a mudança que ele identifica nas narrativas do autor de Pamela acaba tornando-se, como já assinalamos, padrão das práticas romanescas dali em diante, com destaque para a obra de Honoré de Balzac.

\footnotetext{
${ }^{4}$ Assinalo que, em face da curta extensão do presente artigo, deixo de lado as possíveis diferenças entre os campos conceituais dos séculos XVIII e XIX, dentro dos quais os estatutos da "observação" e "imaginação" adquirem significados específicos.
} 
O nosso interesse pelo artigo de Alcides Lima reside na posição cíclica de seu argumento que deixa entrever o caráter dialético que constitui o gênero dentro do arco histórico que vai do século XVIII à segunda metade do XIX: sem nunca se afastar da imaginação que o transforma em produto ficcional, o romance adere ao real que tematiza. Nesse sentido, observação e imaginação não são termos excludentes e nem mesmo o seriam se a oposição fosse em relação ao experimentalismo de Zola, pois, fora de suas condições pragmáticas de realização, a experiência é, em qualquer romance, ficcionalização do próprio procedimento científico.

$\mathrm{Na}$ verdade, o problema não se encontra em toda a tradição romanesca, mas na manifestação recente do gênero que se tornou hegemônica durante certo período a ponto de ser ainda perceptível em um romance presumivelmente naturalista como $O$ mulato. Referimo-nos aqui ao romance romântico. Conforme procuramos demonstrar, há um paralelo possível entre a situação histórica do realismo setecentista de Richardson, como identificado por Diderot, e a do naturalismo de Zola incensado por Alcides Lima: ambas as situações reagem ao suposto privilégio concedido à imaginação pelos romancistas. Entretanto, o paralelismo não se mostra tão simples assim, na medida em que se percebe que a observação não é suficiente como traço distintivo do naturalismo não só porque já se encontrava nos Setecentos inglês como também no romance romântico. Nesse sentido, a modalidade do gênero contra a qual cada situação encontra seu fundamento histórico não é a mesma: o feérico a que se contrapunha o realismo de Richardson retorna ao século XIX sem que se abandone o que foi iniciado pelo autor de Clarissa, ou seja, o seu próprio realismo. E dessa dialética entre imaginação despropositada e representação simples da vivência comum é que se nutre o romance romântico, espécie de realismo feérico como aquele praticado por José de Alencar. Daí as dificuldades enfrentadas pelo autor cearense na década de 1870 . No que se segue, trataremos do tema, lembrando apenas que não analisaremos diretamente a sua obra, mas sim a crítica em torno dela no contexto histórico referido.

\section{0 romance romântico alencariano}

Depois de dois anos envolvido com o cargo de Ministro da Justiça, José de Alencar retorna à cena literária em 1870 com dois 
romances publicados em sequência: A pata da gazela e $O$ gaúcho, ambos assinados pelo pseudônimo Sênio e impressos pela editora Garnier. ${ }^{5}$ De imediato, apesar de inaugurarem nova fase como parece atestar o inédito pseudônimo, os dois livros vinculam-se aos trabalhos anteriores do autor: o primeiro associa-se, pelo emprego de dicção socialmente contemporânea centrada no dia a dia da corte, à linhagem da qual fazem parte Cinco minutos (1856), A viuvinha (1860), Lucíola (1862) e Diva (1864), e o segundo, por conta da abordagem histórica em cenários provincianos, àquela composta por $O$ guarani (1857), Iracema (1865) e As minas de prata (1865-66). A crítica coetânea logo notou o vínculo, como escreve Luiz Guimarães Junior: "Sênio! G.M! J. Al. - são três pseudônimos distintos em um só talento verdadeiro" (GUIMARÃES JUNIOR, 1870, p. 1, grifo do autor).

Nesse mesmo artigo, no qual se encontra o recenseamento dos supracitados romances, com a ressalva de que, nessa data, apenas o primeiro volume de $O$ gaúcho havia saído, Guimarães Junior já aponta para certa diretriz crítica que vai em geral orientar a recepção dos romances alencarianos no decorrer do decênio. Após resumir o enredo de A pata da gazela, escreve o poeta carioca:

Os tipos principais, Horácio de Almeida e Amélia são falsos. Não há na sociedade brasileira um homem como o leão, espécie de desœuvré da regência francesa: nem em sociedade alguma do mundo é possível encontrarse uma moça como a Amélia, a gazela do romance. (GUIMARÃES JUNIOR, 1870, p. 1)

Sobre o segundo romance, vale destacar o que se segue: "no Gaúcho o romancista deixou a pena graciosa com que brinca, e excita a acompanhá-lo as imaginações travessas, para abrir novo campo às lutas do romance contemporâneo." (GUIMARÃES JUNIOR, 1870, p. 1). E, ao contrário dos tipos falsos de $A$ pata da gazela, o do protagonista de $O$ gaúcho "é admirável de expressão e natureza" (GUIMARÃES JUNIOR, 1870 , p. 1). Percebe-se na reação crítica do autor de $A$ família agulha certa ambiguidade uma vez que, mesmo sob a égide da observação literária com a qual ele desqualifica o primeiro romance, ele ainda se

\footnotetext{
${ }^{5}$ Até então, o último romance do autor tinha sido As minas de prata, impresso em seis volumes entre 1865 e 1866.
} 
baseia, para valorizar o segundo, no êxtase provocado pelo desenho de um personagem que remete, romanticamente, ao "Cid campeador" (GUIMARÃES JUNIOR, 1870, p. 1).

Entretanto, já em 1871, a ambiguidade cede lugar a uma posição mais assertiva em que a observação parece reinar absoluta como vimos no ensaio de Alcides Lima impresso dez anos depois. A entrada em cena do cearense Franklin Távora é sintoma dessa mudança. Em uma série de cartas sob o pseudônimo Semprônio, publicada no jornal Questões do Dia, de propriedade do português José Feliciano de Castilho, ele discute dois romances alencarianos, O gaúcho e Iracema. A despeito do caráter panfletário que envolve o periódico em questão, interessado em combater as ideias políticas de José de Alencar, o que de imediato minimiza a possibilidade de isenção crítica do autor de Lourenço, o que importa destacar nas cartas é a recorrência do critério observacional. Como Iracema é uma publicação de 1865, vamos nos deter apenas na sua apreciação sobre $O$ gaúcho.

Logo na primeira carta, Távora inicia com a apresentação do que ele julga ser o perfil fisiológico e cultural do gaúcho. Em seguida, ele assinala a fonte do perfil: $O$ guarani, de Gustave Aimard, texto originalmente publicado em 1864, e que no Brasil teve uma tradução divulgada em $O$ Globo, entre outubro de 1876 e abril de 1877 . E a legitimidade do livro de Aimard deve-se ao fato de que o leitor pode encontrar aí o "tipo exato e não a fábula raquítica", uma vez que "o historiador francês estudou em pessoa os costumes da vida nômade do pampa. Escreveu como quem viu, e não como quem ideia." (TÁVORA, 2011, p. 14). Daí que, por sua veracidade observacional, os personagens "não são pálidas visões, criaturas disformes, descoradas, confusas e em contraposição à verdade natural e etnográfica." (TÁVORA, 2011, p. 14).

Mais adiante, já na segunda carta, Távora identifica a mesma qualidade só que agora no escritor norte-americano James Fenimore Cooper. Depois de compará-lo a Walter Scott, mostrando a sua superioridade sobre o romancista escocês na realização daquilo que se entende por "romance de nacionalidade" (TÁVORA, 2011, p. 50), uma vez que Cooper não dispôs de predecessores que se ocupassem da observação da natureza nativa, tornando-o assim um pioneiro, pois ele imita diretamente a natureza e não outros escritores do passado, Távora o aproxima de Sênio. E o ponto de contato é serem ambos americanos. Entretanto, a analogia não vai além desse traço, pois enquanto Cooper 
“daguerreotipa a natureza, Sênio, à força de querer passar por original, sacrifica a realidade ao sonho da caprichosa imaginação." (TÁVORA, 2011, p. 52). Daí o limite do seu método criativo:

[...] Sênio tem a pretensão de conhecer a natureza, os costumes dos povos (todas essas variadas particularidades, que só bem apanhamos em contato com elas) sem dar um só passo fora de seu gabinete. Isto o faz cair em frequente inexatidões, quer se proponha a reproduzir, quer a divagar na tela. Por que não foi ao Rio Grande do Sul, antes de haver escrito o Gaúcho? (TÁVORA, 2011, p. 53)

Método obviamente falível, pois, segundo reitera o crítico, "não é a leitura isolada, embora dos mais escolhidos modelos, que dará a expressão fiel da natureza." (TÁVORA, 2011, p. 54).

Para o nosso interesse, é desnecessário analisar todas as cartas de Semprônio sobre $O$ gaúcho, uma vez que a sua análise da história de Manuel Canho não vai além da constatação da incompetência observacional de José de Alencar. Contudo, importa destacar que a imagem que emerge de sua leitura acaba forjando o modelo de abordagem crítica do autor de Iracema com base no qual boa parte dos críticos do decênio de 1870 vai ler a sua obra, ou seja, como produto típico de um escritor de gabinete. Nesse sentido, o "romance de nacionalidade" alencariano carece do conhecimento adequado da natureza porque, ao inventá-la, deixa de apresentar os espaços e os costumes nativos como resultado de um processo fidedigno de observação.

Não é difícil perceber que o acréscimo crítico aqui é mínimo, pois, para Távora, trata-se de escrever, sobre as mesmas bases, o romance que não teria sido escrito por Alencar. É como se o autor de Lucíola não tivesse aprendido bem a lição dos grandes mestres do "romance de nacionalidade", Scott e Cooper, naquilo que há de mais específico na nova modalidade - nova em contraposição ao padrão do realismo setecentista - e que se traduz na capacidade do gênero de expressar o elemento nacional por excelência pela observação direta da cor local. Uma vez que a tarefa não foi cumprida pelos predecessores, surge a necessidade de constantemente reinventar a literatura brasileira na medida em que a sua gestação depende do conhecimento apurado da realidade, como se pode ler cinco anos depois no prefácio que o próprio Távora escreve para o seu mais afamado romance, $O$ Cabeleira: "As 
letras têm, como a política, um certo caráter geográfico; mais no norte, porém, do que no sul abundam os elementos para a formação de uma literatura propriamente brasileira, filha da terra." (TÁVORA, 1975, p. xxvii). Curiosamente, Visconde de Taunay, no capítulo de suas Memórias em que discorre exatamente sobre José de Alencar, sobretudo sobre o seu desconhecimento da natureza pátria, reiterando assim o estigma do escritor de gabinete, teria chegado à mesma conclusão a respeito de seu consagrado romance, Inocência: "No meu pensar bem leal, talvez ingênuo, por isso mesmo e de bastante modéstia, este romance é a base da verdadeira 'literatura brasileira'." (TAUNAY, 1948, p. 233). ${ }^{6}$ Como se sabe, a narrativa de Taunay, publicada em 1872, versa sobre conflitos passionais ocorridos entre personagens no interior da província de Mato Grosso (hoje Mato Grosso do Sul), região cuja descrição estaria baseada em suas anotações de viagem realizadas durante o período em que, membro de expedição militar, ele participa da Guerra do Paraguai; anotações que também serviram de fonte a outro importante livro do autor, A retirada da Laguna, de 1871, originalmente escrito em francês. Independente de perscrutar o sertão de Pernambuco, Mato Grosso ou o pampa gaúcho e a despeito de cada região examinada não coincidir com o território nacional em sua integralidade, havendo inclusive dissensões culturais, como se nota na postura assumida por Távora ao privilegiar a "literatura setentrional" em oposição à "austral", o que deve prevalecer no "romance de nacionalidade" é a vocação observacional isenta da intervenção excessiva da imaginação autoral.

Ao final da década, em ensaio que se inicia no periódico $O$ vulgarizador um pouco antes da publicação de $O$ mulato, em 1879 , e que é retomado e finalizado em 1881, na Revista Brasileira, saindo em livro no ano seguinte com o título José de Alencar: perfil literário, Araripe Júnior oferece a primeira leitura mais abrangente do romancista cearense. ${ }^{7}$ Diferentemente da intervenção ocasional típica de uma resenha bibliográfica, como a de Luís Guimarães Junior, e da diatribe característica de posicionamento crítico deliberadamente pessoal, como

\footnotetext{
${ }^{6}$ É importante assinalar que a redação das memórias de Taunay foi concluída em 1892 , mas o livro só foi publicado em 1946.

${ }^{7}$ Vale lembrar que Joaquim Nabuco, no decorrer da polêmica com Alencar em 1875 , acabou analisando um conjunto significativo da produção do autor de Senhora sem, contudo, apresentar o caráter sistemático empreendido pelo crítico cearense.
} 
se vê em Franklin Távora, o texto do autor de Luizinha é uma tentativa mais apurada de, com base nas concepções críticas de Hippolyte Taine, seguir passo a passo a produção alencariana desde a origem, considerando inclusive as disposições intelectuais gestadas na infância, até os seus últimos escritos. Diante da importância desse trabalho para a compreensão da literatura de Alencar, bem como de sua recepção crítica no período histórico aqui destacado, vale a pena nos debruçarmos mais detidamente sobre ele.

\section{0 salto naturalista}

Conforme escreve Araripe Júnior na "Advertência" à primeira edição de seu livro, o seu intuito não era "escrever a vida de José de Alencar. Da biografia tirei quanto fosse bastante para explicar a feição e as modificações por que passou o literato, e por esta razão dei a este trabalho o título de perfil literário." (ARARIPE JÚNIOR, 1958, p. 133, grifo do autor). Por sua vez, no prefácio à segunda edição de 1894 , respondendo às considerações de um resenhista do jornal maranhense $O$ País, que foi a única voz destoante entre as que bem acolheram o seu livro à época de seu lançamento em $1882,{ }^{8}$ o crítico cearense define a sua proposta como "a história da evolução do espírito artístico de José de Alencar e, paralelamente, a morfologia, afiliação e a transformação dos caracteres dos personagens dos seus romances." (ARARIPE JÚNIOR, 1958 , p. 132). De fato, embora a biografia compareça, fundamentando boa parte de sua argumentação, o seu objetivo não se limita à narrativa da trajetória de vida de Alencar, como se percebe pelo modo como ele organiza a sua escrita, dividida em sete capítulos, contemplando cinco momentos do percurso criativo do escritor: "gênese artística", "explosão", "ação e reação", "declínio" e "crítica" - o terceiro e o quarto itens são desenvolvidos em dois capítulos. Cada momento articula circunstâncias biográficas com aspectos da formação artística em um processo evolutivo que se manifestaria nas realizações literárias alencarianas.

Para que se tenha ideia desse percurso, destacamos o seguinte trecho que se encontra nos parágrafos iniciais do primeiro capítulo, cujo

\footnotetext{
${ }^{8} \mathrm{O}$ artigo a que se refere Araripe Júnior foi estampado em $O$ País, distribuído em quatro partes nos dias 14 de janeiro, 04, 14, 21 e 22 de fevereiro de 1883, sempre com o pseudônimo F.C. Trata-se provavelmente do jurista maranhense Francisco José Viveiros de Castro (1862-1906).
} 
período cronológico da biografia alencariana tratado pelo crítico se situa entre os anos de 1829 e 1852, ou seja, entre o seu nascimento, o término do curso de Direito e a mudança definitiva para o Rio de Janeiro, onde começa a advogar: "Creio que tudo seja explicável em um trabalho de arte; e, quanto a José de Alencar, afirmo que a boa conformação de seu talento não teria tomado a direção que tomou sem a índole que recebeu com o sangue." (ARARIPE JÚNIOR, 1958, p. 137). A herança genética a que alude o crítico diz respeito, por um lado, à linhagem paterna da qual se originaria o seu "gênio sobranceiro", cuja fonte é a avó do autor, Bárbara de Alencar, que atuou, ao lado dos filhos, inclusive o pai do romancista, José Martiniano de Alencar, nos principais movimentos separatistas da província de Pernambuco em 1817 e 1824, e, por outro, à influência materna, da qual adviria a sua "potente imaginação". O resultado é a formação de uma individualidade artística que não se deixa dominar pelos mais variados estímulos externos, incluindo os literários, ao mesmo tempo que se expressa pelo "mais caprichoso dos artistas americanos" (ARARIPE JÚNIOR, 1958, p. 138). Surgem daí, segundo Araripe Júnior, a perspectiva idealista e o estilo gracioso que caracterizam o temperamento criativo de José de Alencar.

A partir da conformação, Araripe Júnior vai analisar a produção alencariana procurando demonstrar que ela é manifestação concreta desse temperamento, especialmente no início, quando, de acordo com a lei de Taine da evolução criadora, o artista se mostra autenticamente inspirado - segundo ainda o crítico francês, o segundo momento seria o da repetição de si mesmo, consequentemente o do declínio. A justificativa da lei encontra respaldo na analogia fisiológica: como qualquer organismo vivo que evolui na direção de seu pleno desenvolvimento para depois se degenerar, a sensibilidade humana também segue o mesmo curso, consequentemente a arte, como produto diretamente ligado a essa faculdade. Sob essa óptica, os primeiros textos de Alencar apresentam a melhor conformidade com a sua disposição de espírito, em que tudo se sujeita ao seu idealismo e ao seu estilo grácil, como aparece plenamente realizado em $O$ guarani. É nessa obra que, para Araripe Júnior, o estilo alencariano encontra a sua expressão definitiva no feminino representado pela figura de Ceci, expressão que, mesmo quando arrefece, não seria nunca abandonada pelo autor de $O$ sertanejo.

Entretanto, é aí também, como em toda a sua obra, que Araripe Júnior vai identificar a sua principal deficiência: a hipertrofia do estilo. 
Como tudo em sua disposição de espírito é linguagem, forma e estesia, Alencar reduziria qualquer realidade tematizada ao seu idealismo grácil. A sua índole literária seria assim refratária à análise e à observação. Em O guarani, o efeito da hipertrofia percebe-se na forma como o autor tenta decifrar o passado, idealizando-o ao invés de comprová-lo, produzindo desse modo uma imagem do Brasil só possível em sua imaginação. Escrevendo sobre a cena final do romance de 1857, diz o crítico cearense: "a saudade, que deixa na alma este final vago e vaporoso, desculpa bem as violências cometidas por essa musa feminil contra os documentos da vida real." (ARARIPE JÚNIOR, 1958, p. 168).

A hipertrofia fica ainda mais evidente quando Alencar resolve escrever peças teatrais. Como ele adota como matriz o teatro realista francês de Alexandre Dumas Filho, Émile Augier e Octave Feuillet, o problema intensifica-se, pois "eram antipáticas à sua índole as audácias dessa escola.” (ARARIPE JÚNIOR, 1958, p. 171).

O ponto agora que vale destacar no perfil apresentado por Araripe Júnior alude ao momento no qual ele trata do declínio da sensibilidade artística de José de Alencar. E é aqui que $O$ gaúcho exerce um papel fundamental. Como já assinalamos, em seu modelo interpretativo, a biografia caminha pari passu com a evolução artística do autor cearense sem, contudo, se tornar o traço preponderante ou aquele que, em última instância, condiciona as obras. O que não implica dizer que ela não possa, em determinadas circunstâncias, por conta de pressões sofridas por adversidades no convívio social do autor, se converter em elemento capaz de alterar certas características de sua predisposição literária. É o que se dá no final da década de 1860. Em 1868, Alencar foi chamado para participar do Gabinete de 16 de julho, presidido por Joaquim José Rodrigues Torres, o Visconde de Itaboraí, ocupando a pasta de Ministro da Justiça. Durante o exercício da função, Alencar resolve tentar uma das duas vagas para o Senado pela província do Ceará, cargo que, segundo consta, representava a realização do grande sonho político de sua vida que coroaria uma carreira até então bem-sucedida - desde 1861, o autor vinha sendo eleito deputado geral pela mesma província. Alencar é o primeiro mais votado em uma lista sêxtupla, mas é preterido por d. Pedro II, que escolhe o segundo e o quinto colocados. Junta-se a esse dissabor político a sua demissão do ministério, antes mesmo da dissolução do gabinete, em virtude das controvérsias em que se vê envolvido com companheiros de outras pastas, em especial com João Maurício Wanderley, o Barão de Cotegipe. 
Ora, na leitura de Araripe Júnior, a desilusão política decorrente do drama que acabamos de narrar teria sido suficiente para mudar o rumo assumido pelo seu temperamento artístico desde o início, consequentemente "o autor ridente do Guarani não [seria] o mesmo do sombrio Gaúcho." (ARARIPE JÚNIOR, 1958, p. 214). E ao assumir o novo pseudônimo Sênio, com o qual ele assina, além de $O$ gaúcho, outros quatro romances do período, A pata da gazela (1870), O tronco do ipê (1871), Sonhos d'ouro (1872) e Guerra dos mascates (1873-74), Alencar parece corroborar a interpretação do autor de seu perfil quando escreve o prefácio à história de Manuel Canho:

Porventura escolhendo aquela palavra [Sênio], quis o espírito indicar que para ele já começou a velhice literária, e que estes livros não são mais as flores da primavera, nem os frutos do outono, porém sim as desfolhas do inverno? Talvez. Há duas velhices: a do corpo que trazem os anos, e a da alma que deixam as desilusões. Aqui, onde a opinião é terra sáfara, e o mormaço da corrupção vai crestando todos os estímulos nobres; aqui a alma envelhece depressa. E ainda bem! A solidão moral dessa velhice precoce é um refúgio contra a idolatria de Moloc. (ALENCAR, 1967, p. 81)

Afora o fato de que, pela primeira vez, segundo Araripe Júnior, o autor de Iracema não renderia mais culto à mulher como expressão de seu idealismo grácil, em $O$ gaúcho o efeito mais grave dessa mudança estaria relacionado à misantropia que, representada em personagens como Manuel Canho, seria responsável por disseminar em suas narrativas as desilusões que agora orientam a sua disposição de espírito. Entretanto, a mudança de rumo não dissipa a índole primeira, pois é exatamente da contrariedade que surge o desvio: a misantropia é o resultado do idealismo que não encontra o seu lugar no mundo, razão pela qual não consegue ver nele senão a sua própria imagem. Em ambos os casos, o estatuto de sua disposição não é afetado, pois é sempre a imaginação do autor que prevalece, seja a ridente ou a sombria.

O problema da interpretação apresentada por Araripe Júnior, o mesmo que, como vimos, aparece em Távora, mas não pelas mesmas razões, reside no fato de que ela se faz pela ausência: Alencar deveria ter escrito o romance que não escreveu. Daí o crítico cearense não encontrar aquilo que procura na obra de seu conterrâneo: 
O guarani constitui o lado oposto às misérias humanas. Nem um traço, de longe sequer, que recorde Dickens ou Balzac. Percorrendo a galeria inteira de seus personagens, não encontro um só caráter bilioso ou apoplético, em cujo fundo se destaquem as violências reais da natureza humana, os horrores da fisiologia, e que represente a revolta social, a apoteose de um vício ou de uma classe, tremendas escavações nos abismos da consciência. (ARARIPE JÚNIOR, 1958, p. 163)

Não é despropositado ler na passagem acima a plataforma do romance naturalista. Nesse sentido, diferentemente de Alcides Lima que, ao falar de naturalismo, não fez mais do que reproduzir o padrão do realismo setecentista, a contribuição crítica de Araripe Júnior traz o dado novo da perspectiva científica na abordagem da arte. A despeito do problema apontado, que se nota menos na análise que ele faz das disposições artísticas do autor do que na tentativa de interpretá-las nas próprias obras, a perspectiva adotada mostra-se suficientemente sólida a ponto de se tornar o paradigma crítico que seria seguido nas décadas seguintes.

\section{Conclusão}

Se retornarmos mais uma vez à questão do romance tal como apresentada por Diderot, podemos sustentar que o critério adotado pela crítica da década de 1870 em relação à obra de Alencar, especialmente O gaúcho, supõe que o realismo do romance não chegara a se manifestar na literatura brasileira até então, apesar da contribuição de autores como Teixeira e Sousa, Joaquim Manuel de Macedo, entre outros, cuja produção vinha desde os anos de 1840 . É como se para essa crítica a ruptura no gênero identificada pelo filósofo francês na obra de Richardson não tivesse cruzado o oceano e o romance desses autores correspondesse àqueles, feéricos e frívolos, contra os quais as realizações do romancista inglês se voltavam. Além disso, considerando a direção apontada pelo trabalho de Scott e reverberada de modo original pelas realizações de Cooper, em que a expressão de nacionalidade coaduna-se com o realismo do gênero em sua faceta setecentista, pode-se dizer que o romance brasileiro não tinha sido ainda escrito, muito menos por aquele a quem alguns já atribuíam a paternidade da modalidade nacional do gênero, José de Alencar. Se 
isso fica evidente sobretudo em Távora, em Araripe Júnior a direção é outra: a obra alencariana não deixa de ser nacional, apenas que, toldada pelo estilo que tudo contamina, não lhe foi possível atingir o âmago da própria nacionalidade. Se um romance como O gaúcho, com a pretensão de captar a cor local em seus mais variados matizes - cultural, geográfico e histórico -, não seria capaz de cumprir tal meta, por ser produto de um escritor de gabinete, é curioso que o método empregado pelos seus críticos consista no confronto das formulações alencarianas com os respectivos matizes, em uma espécie de teste de fidedignidade, no qual muitas vezes tornava-se necessário a interposição de outras narrativas, como o faz Távora, quando insere no debate o livro de Gustave Aimard, para que ele mesmo tivesse acesso a um cenário que lhe era igualmente distante, embora útil como contraprova crítica.

Por linhas tortas, a crítica da década de 1870 deixa entrever o realismo feérico de José de Alencar.

\section{Referências Bibliográficas}

ALENCAR, J. O gaúcho. In: . Romances ilustrados de José de Alencar. Rio de Janeiro: José Olympio, 1967. v. 4, p. 1-169.

ARARIPE JÚNIOR, T. A. Perfil literário de José de Alencar. In:

Obra crítica de Araripe Júnior. Rio de Janeiro: Ministério da Educação e Cultura; Casa de Rui Babosa, 1958. v. 1, p. 129-258.

DIDEROT, D. Elogio a Richardson. In:

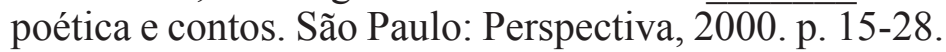

GUIMARÃES JUNIOR, L. Revista do domingo. Diário do Rio de Janeiro, Rio de Janeiro, p. 1, 18 dez. 1870.

LIMA, A. O mulato, por Aluísio Azevedo. Província de São Paulo, São Paulo, 26 maio, p. 1, 1881.

MARTINS JUNIOR, I. A poesia científica: escorço de um livro futuro. Recife: Imprensa Industrial, 1914.

TÁVORA, F. O Cabeleira: história pernambucana. São Paulo: McGrawHill, 1975.

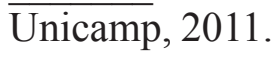

. Cartas a Cincinato: estudos críticos por Semprônio. São Paulo: 
TAUNAY, V. Memórias do visconde de Taunay. São Paulo: Instituto do Progresso Editorial, 1948.

ZOLA, É. O romance experimental e o naturalismo no teatro. São Paulo: Perspectiva, 1982. 